\title{
Research article Effectiveness of Pilates exercises on non-specific low back pain to determine pain and disability
}

\author{
Manikandan P. ${ }^{1}$, Mohan Kumar G. ${ }^{2}$, Rajalaxmi V. ${ }^{2}$, Priya C. ${ }^{3}$, Yuvarani G..${ }^{4}$, Tharani G. ${ }^{4}$, Kamatchi K. ${ }^{4}$, Vaishnavi ${ }^{4}$, \\ Muthu Raj G. ${ }^{4}$
}

${ }^{1}$ Physiotherapist, ${ }^{2}$ Professor, ${ }^{4}$ Assistant Professor, Faculty of Physiotherapy, ${ }^{3}$ Associate Professor, Department of Biotechnology, Dr. MGR Educational and Research Institute, Chennai, Tamil Nadu, India

(Received: June $2020 \quad$ Revised: October $2021 \quad$ Accepted: November 2021)

Corresponding author: Mohan Kumar G. Email: mohankumar.physio@drmgrdu.ac.in

\begin{abstract}
Introduction and Aim: Low back discomfort is one of the commonest musculoskeletal problems. The Pilates exercises are an approach to stretching and strengthening techniques and specifically train all the core muscles. The intend of the current study was to verify the influences of the Pilates exercises among pain and disability among patients with Non-specific Low Back Pain (NSLBP).
\end{abstract}

Materials and Methods: A 100 non-specific low back pain subjects were randomly selected for this experimental study. The study includes of non-specific LBP age group between 25 to 40 years, both male and female patients with pain and disability and this study excludes spinal fractures and Pregnant Women. The estimations were taken utilizing Visual Analogue scale (VAS), Patient Specific Functional Scale (PSFS) and Modified Oswestry Low Back Pain Disability Questionnaire (MODQ). Subjects are allotted in two groups, Group A (Pilates group) receives Pilate's exercise and Group B (conventional group) receives conventional exercise. Exercises were given for 3 times a week for 12 weeks and a regular follow up was done for every 4 weeks.

Results: Group A (Pilates group) were found to be more effective than Group B (conventional group). It shows a highly significant difference in mean values at $\mathrm{P} \leq 0.001$. This implies that Pilates exercise is more beneficial in decreasing pain and functional disability.

Conclusion: On comparing the mean values, Group A (Pilates group) showed significant improvement at the end of the study when compared with Group B (conventional group).

Keywords: Non-Specific low back pain; Pilates exercises; visual analogue scale; patient specific functional scale; modified Oswestry LBP disability questionnaire.

\section{INTRODUCTION}

$\mathrm{B}$ ack pain is a usual reason of disability and work loss which constitute a huge socioeconomic lade in developed countries (1). It was reported that approximately $60 \%$ to $80 \%$ of adults were affected with low back discomfort during their lifetime (2). LBP is well depicted as pain bound under the limit of the last costal edge above the distal gluteal line, with or without lower extremity pain, and it is one of the most natural or universal reasons for inadequacy.

Chronic low back discomfort and persistent low back pain discomfort for three months or more were a compelling general medical issue including significant expenses associated with treatment ((3-5). As per the Global Burden of the illness study data, low back discomfort is one of the foremost basic conditions among 291 wellbeing conditions, just as the condition that influences more person in the world in terms of years lived with inability (6).

Non-specific low back torment speaks to $90 \%$ all things considered. Various variables can impact the mechanical balance of the lumbar area, prompting instability that can trigger low back discomfort (7).
Hayden et al. distributed an audit evaluating the efficacy of exercise in contrast with different medicines or no treatment at all and reasoned that therapeutic exercise is successful at lessening pain and improving function in adults with chronic nonspecific low back discomfort (8). Much of the writing looking at interminable LBP and exercise intercessions study a populace whose pain and disability show in "deconditioning disorder" as portrayed by Mayer (9).

The Pilates strategy is a one-of-a-kind arrangement of extending and reinforcing practices created by Joseph H Pilates almost 90 years back that utilizes sets of controlled, exact developments and the utilization of special equipment. The Pilates Method is a one-of-akind way to accord with preparing at the tip of the priority list body mind body awareness and control of movement and posture. The Pilates strategy depends on 6 fundamental principles: precision, concentration, centring, control, fluidity, and diaphragmatic breathing (10).

The motivation behind physical preparation utilizing the Pilates method is to accomplish better working of the body dependent on the reinforcing of the 
'powerhouse', a term referring to the lower trunk that supports the body (11). The strategy's principle trademark is the presentation of the activities with isometric contraction of the transversus abdominis, perineal, gluteal, and multifidus muscles during diaphragmatic breathing, known as "Powerhouse (12).

The neuromuscular requests of traditional Pilates methods can be very high and along these lines a change of this technique is important for application to physiotherapeutic interventions. Traditional Pilates procedures, concentrating on postural balance and controlled development. Specific accentuation, in any case, was set on specific muscle enactment systems thought to balance out the lumbar-pelvic region. An modified Pilates way to deal with improve stance and control development would thus be apt to be bolstered inside a hypothetical setting of neuromuscular control and expands upon the idea of strength about a local spinal segment. The role of the extensors of hip and the gluteus maximus is believed to be central to stability and control in the lumbarpelvic area (13). The muscle gluteus maximus may assume a significant job in lumbar-pelvic mechanics and burden move from the lumbar spine to the pelvis and lower extremities (14).

Janda portrays a trademark "pseudoparesis" of the muscle gluteus maximus among LBP, described by hypotonia and a lag in activation (15). An attendant unbalance in the functional length or enrolment of the hamstrings or superficial lumbar erector spinae relative to the gluteus maximus has been related with LBP (16). The vast majority with nonspecific lower back pain recovers rapidly, on occasion; the recovery can take longer time. It tends to be said that nonspecific lower back pain varies as per the movement done and the posture of the body (17).

Chronic nonspecific low back discomfort is a typical musculoskeletal condition regularly resulting in physical inactivity and disability (18). Physiotherapy is a better option for pain relief \& aims particularly at pain relief initially and then at improving spinal mobility and muscle power and endurance (19).

The conventional exercise is one of the simplest exercises however effective to train and enhance the lower back. The conventional exercise is proficient for promoting muscle strength and endurance in the erector spinae, it keeps from damage and postural issues in the spine. The objective of the study is to find the influences of Pilates exercise on subjects with non-specific low back discomfort to determine pain and functional disability. Null hypothesis states there are no significant changes in the efficacy of
Pilates exercise and conventional exercise in nonspecific low back discomfort within the groups.

\section{MATERIALS AND METHODS}

An amount of 100 subjects with low back pain with both genders was taken by simple random sampling method at A.C.S medical college and hospital. An experimental study was conducted for $45 \mathrm{~min}$ per day for 3 session per week for 12 weeks using Pilates exercises and conventional exercises with an inclusion criteria for both genders with nonspecific chronic low back discomfort of age group between 25-40 years, disability, pain, Long standing persistent Non-specific Low Back Pain (NSLBP) and Recurring Non-specific Low Back Pain (NSLBP) and this study excludes Spinal fracture, Rheumatic disease, Systemic metabolic disorder, Chronic pain syndrome, Pregnant Women, Multiple Sclerosis or Diabetes with neurological symptoms.

\section{Intervention}

A total of 100 subjects fulfilling the criteria were preferred with simple random sampling method The Subjects were allotted into 2 groups. Group A (Pilates group) consists of 35 subjects were received Pilates exercises for core strengthening and stabilization by adding resistance which forces exercises to activate their core strengthen muscles of lumbar region. Additionally, exercise acts as deeper core stabilization. The exercises are given for the 45 minutes per day for 3 sessions per week for 12 weeks. The Pilates exercises were chest lift, spinal twist in supine, hamstring stretch, rolls back and Leg Reach and Kneeling Arm Kneel.

Group B (conventional group) having 35 subjects were received conventional exercises that are CAT \& CAMEL exercises, SLR (straight leg rising), pelvic tilt, lumbar rotation, prop up on elbows, piriformis stretches, hip flexors exercise. The exercises are given for the 45 minutes per day/3 sessions per week/12weeks. Patient consent was obtained by explaining the procedure and said effect of Pilates exercise and conventional exercise. Initially 30 subjects were dropped out based on selection criteria.

Before treatment intervention, pre-test was done by measuring the intensity of respective pain and functional ability of non-specific low back pain using the VAS, PSFS and MODI outcome measures. After regular 4 weeks, 8 weeks, and 12 weeks of intervention of treatment, post-test was done by measure the intensity of respective pain and functional ability of Non-specific low back pain using the VAS, PSFS and MODI outcome measures. 


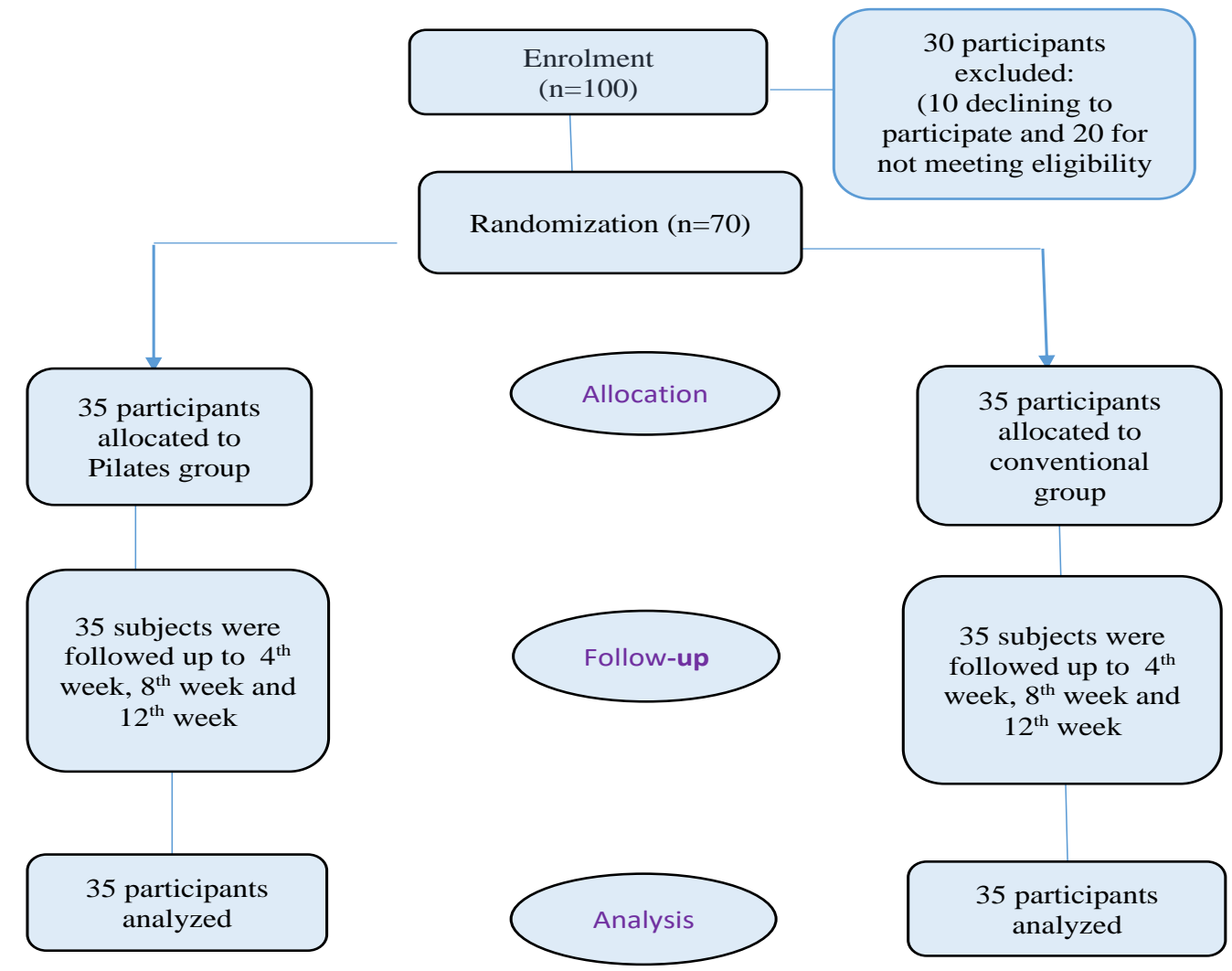

Fig. 1: Consort flow chart of participants in the study

\section{Data analysis}

Table 1: Comparison of pre and post test scores of visual analogue scales (VAS) using T- test between group A and group B

\begin{tabular}{|c|c|c|c|c|c|c|c|c|}
\hline \multirow[t]{2}{*}{ VAS } & \multicolumn{2}{|c|}{ Group A } & \multicolumn{2}{|c|}{ Group B } & \multirow[b]{2}{*}{$\mathbf{t}-$ Test } & \multirow[b]{2}{*}{ f Value } & \multirow[b]{2}{*}{ df Value } & \multirow{2}{*}{$\begin{array}{c}\text { Significance } \\
\text { (P) }\end{array}$} \\
\hline & Mean & S.D. & Mean & S.D. & & & & \\
\hline Pre-test & 6.51 & .818 & 6.34 & .765 & .906 & .367 & 68 & .315 \\
\hline $\begin{array}{l}\text { Post- test } \\
4^{\text {th }} \text { week }\end{array}$ & 5.20 & .584 & 6.06 & .725 & -5.445 & .660 & 68 & .000 \\
\hline $\begin{array}{l}\text { Post- test } \\
8^{\text {th }} \text { week }\end{array}$ & 4.00 & .767 & 4.66 & .482 & -4.293 & .419 & 68 & .000 \\
\hline $\begin{array}{l}\text { Post-test } \\
12^{\text {th }} \text { week }\end{array}$ & 1.51 & .507 & 2.60 & .497 & -9.046 & 1.331 & 68 & .000 \\
\hline
\end{tabular}

Table 2: Comparison of pre and post test scores of Patient Specific Functional Scale (PSFS) using T- test between group A and group B

\begin{tabular}{|c|c|c|c|c|c|c|c|c|}
\hline \multirow[t]{2}{*}{ PSFS } & \multicolumn{2}{|c|}{ Group A } & \multicolumn{2}{|c|}{ Group B } & \multirow{2}{*}{$\mathbf{t}-$ Test } & \multirow[t]{2}{*}{ f Value } & \multirow[t]{2}{*}{ df Value } & \multirow{2}{*}{$\begin{array}{c}\text { Significance } \\
\text { (P) }\end{array}$} \\
\hline & Mean & S.D. & Mean & S.D. & & & & \\
\hline Pre-test & 1.011 & .5503 & .966 & .4814 & .370 & .796 & 68 & .859 \\
\hline $\begin{array}{l}\text { Post- test } \\
4^{\text {th }} \text { week }\end{array}$ & 3.154 & .3567 & 2.451 & .2293 & 9.805 & 14.021 & 68 & .000 \\
\hline $\begin{array}{l}\text { Post- test } \\
8^{\text {th }} \text { week }\end{array}$ & 6.069 & .2742 & 4.400 & .2114 & 28.512 & 5.039 & 68 & .000 \\
\hline $\begin{array}{l}\text { Post-test } \\
12^{\text {th }} \text { week }\end{array}$ & 8.126 & 4003 & 6.318 & .2790 & 21.708 & 5.416 & 67 & .000 \\
\hline
\end{tabular}

Table 3: Comparison of pre and post test scores of Modified Oswestry Low Back Pain Disability Questionnaire (MODQ) using T- test between group A and group B

\begin{tabular}{|c|c|c|c|c|c|c|c|c|}
\hline \multirow{2}{*}{ MODI } & \multicolumn{2}{|c|}{ Group A } & \multicolumn{2}{c|}{ Group B } & & f Value & df Value & $\begin{array}{c}\text { Significance } \\
(\mathbf{P})\end{array}$ \\
\cline { 2 - 9 } & Mean & S.D. & Mean & S.D. & t - Test & & & 0.79 \\
\hline Pre-test & 83.71 & 3.503 & 82.06 & 3.741 & 1.913 & .004 & 68 & .213 \\
\hline Post- test $4^{\text {th }}$ week & 68.69 & 4.086 & 69.80 & 3.402 & -1.240 & 1.398 & 68 & .000 \\
\hline Post- test $8^{\text {th }}$ week & 42.86 & 6.700 & 55.14 & 7.101 & -7.445 & .000 & 68 & .000 \\
\hline Post-test 12 $2^{\text {th }}$ week & 17.03 & 4.239 & 26.46 & 4.203 & -9.344 & .082 & 68 & 68 \\
\hline
\end{tabular}




\section{RESULTS}

On comparing the Mean values of group, $\mathrm{A}$ and group B on VAS Score, it shows significant decrease in the post test Mean values, but (Group A- Pilates) shows $4^{\text {th }}$ week $(5.20), 8^{\text {th }}$ week $(4.00), 12^{\text {th }}$ week (1.51) which has the Lower Mean value is effective than (Group B -conventional) shows $4^{\text {th }}$ week (6.06), $8^{\text {th }}$ week (4.66), $12^{\text {th }}$ week (2.60) at $\mathrm{P} \leq 0.005$.

On comparing the Mean values of group A and group B on PSFS Score, it shows significant decrease in the post test Mean values, but (Group A- Pilates) shows $4^{\text {th }}$ week $(3.154), 8^{\text {th }}$ week $(6.069), 12^{\text {th }}$ week $(8.126)$ which has the Lower Mean value is effective than (Group B -conventional) $4^{\text {th }}$ week $(2.451), 8^{\text {th }}$ week (4.400), $12^{\text {th }}$ week (6.318) at $\mathrm{P} \leq 0.005$.

On comparing the Mean values of group, A and group B on MODI Score, it shows significant decrease in the post test Mean values, but (Group APilates) shows $4^{\text {th }}$ week $(68.69), 8^{\text {th }}$ week $(42.86), 12^{\text {th }}$ week (17.03) which has the Lower Mean value is effective than (Group B -conventional) $4^{\text {th }}$ week (69.80), $8^{\text {th }}$ week (55.14), $12^{\text {th }}$ week $(26.46)$ at $\mathrm{P} \leq$ 0.005 .

On comparing pre-test and post-test within group A and group B on VAS, PSFS and MODI, shows highly significant difference in Mean values of group and at $\mathrm{P} \leq 0.001$. There was a significant difference between 2 groups (Group A and Group B) is improving the pain and functional disability. In group A (Pilates) were more effective than Group B (conventional). This implies that Pilates exercise is more beneficial in improving pain and functional disability.

\section{DISCUSSION}

Low back pain represents a significant general medical issue and an economic load to employers. Back pain has been related with dysfunction and weakness of deeper abdominal muscular strength. These deeper abdominal muscles, including the transverses abdominis (TA), multifidus (MF), pelvic floor muscles, and the stomach muscle will be alluded to all through this paper as the "core muscles." Nonspecific (common) LBP is characterized as LBP not credited to an unmistakable, known explicit pathology. pain can't be credited to pathology or neurological infringement in about of peoples. In the current examination patients between the age gathering of 25 to 40 years and having indications of Non-specific Low Back Pain (NSLBP) were incorporated. The examination was directed to conclude the exercise impact like Pilates and conventional exercise approaching closer Nonspecific Low Back Pain (NSLBP) patients.

In our study 100 participants were selected randomly and then 16 subjects were removed from the study, 14 members did not co-operate in the current study due to personal reasons like job, timings of OPD etc., this current study was to strengthen the lower back and to increase the quality of life in both the male and female.

A comparison has been done on the efficacy of two active interventions; the Pilates exercise and conventional exercise in persons with Non-specific Low Back Pain (NSLBP) for 3-month duration. At the deadline of the interventional program, both groups showed changes in pain scores measured using Visual Analogue scale (VAS), Patient Specific Functional Scale (PSFS) and Modified Oswestry Low Back Pain Disability Questionnaire (MODQ). The efficacy of Pilates technique in individuals with long-winded low back torment and reduction in pain while applying the Pilates approach in treating chronic non-specific low back pain in adults. The literature defines Pilates approach as a mind-body practice that spotlights centre stability, strength, muscle control, flexibility, breathing and posture. Pilates method includes conscious utilization of muscles the trunk to balance out the pelvic-lumbar region. A few investigations are as of now reasoned that Pilates practice is more beneficial to enhance the functional disability and pain.

In this study, Pilates exercises are helpful for treating patients with NLBP, including the pre-test mean value of VAS between Group A (Pilates) 6.51 and Group B (conventional) 6.34, did not show a significant difference. At the end of the 12-week treatment session, the post-test mean values showed a significant difference between Group A (Pilates) $4^{\text {th }}$ week (5.20), $8^{\text {th }}$ week $(4.00), 12^{\text {th }}$ week $(1.51)$ and Group B (conventional) $4^{\text {th }}$ week $(6.06), 8^{\text {th }}$ week (4.66), 12 $2^{\text {th }}$ week (2.60). In group A (Pilates) VAS shows better result than Group B (conventional) (20).

In this study, Pilates exercise are helpful for treating patient with NLBP, including the pre-test mean value of PSFS between Group A (Pilates)1.011 and Group B (controlled) .966 did not show a significant difference. At the end of the 12-week treatment session the post-test mean values showed a significant difference between Group A (Pilates) $4^{\text {th }}$ week (3.154), $8^{\text {th }}$ week $(6.069), 12^{\text {th }}$ week $(8.126)$ and Group B (conventional) $4^{\text {th }}$ week $(2.451), 8^{\text {th }}$ week (4.400), 12 ${ }^{\text {th }}$ week (6.318). In the Group A (Pilates) PSFS shows better result than Group B (conventional) (20).

In this study, Pilates exercises are helpful for treating patients with NLBP, including the pre-test mean value of MODI between Group A (Pilates) 83.71 and Group B (conventional) 82.06 did not show a significant difference. At the end of the 12-week treatment session, the post-test mean values showed a significant difference between Group A (Pilates) $4^{\text {th }}$ week $(68.69), 8^{\text {th }}$ week $(42.86), 12^{\text {th }}$ week $(17.03)$ and Group B (conventional) $4^{\text {th }}$ week $(69.80), 8^{\text {th }}$ week (55.14),12 ${ }^{\text {th }}$ week (26.46). In Group A (Pilates) 
MODI shows better result than Group B (conventional) (21).

The results of the study statistically indicated by the described data, such as mean and standard deviation, which indicated improvement in the terms of pain reduction and ability at the end of the treatment in both the groups. Correlate the results obtained from the two groups, the results of the study showed that Pilates exercise (Group A) showed significant $\mathrm{P} \leq$ 0.001 improvements than conventional exercise (Group B).

\section{CONCLUSION}

The study demonstrated that patients who having NLBP decrease pain by using Pilates approach and conventional exercise with reference to the statistical analysis done from the data collected using it is concluded there is a more significant improvement in Pilates approach in pain reduction and functional ability and also minimal reduction with conventional exercises. On comparing the mean values obtained from both group A and group B, group A showed significant decrease at the end of the current study compared with group B. Thus, Pilates exercise is an effective non-pharmacological, non-invasive therapy which helps reduction in pain and improving functional ability without any side effects and hazardous. Therefore, this study proved that Pilates exercise and conventional exercise play a vital role in treating NLBP. Therefore, this study rejects the null hypothesis.

\section{CONFLICT OF INTEREST}

The author(s) declared no potential conflicts of interest.

\section{REFERENCES}

1. Kermode, F. Benefits of utilising real-time ultra- sound imaging in the rehabilitation of the lumbar spine stabilising muscles following low back injury in the elite athlete: a single case study. Physical Therapy in Sport. 2004; 5: 13-16.

2. Biering-Sorensen, F. A prospective study of low back pain in a general population. I. Occurrence, recurrence and aetiology. Journal of Rehabilitation Medicine. 1983; 15: 7179.

3. Burton, A. K., Balague, F., Cardon, G., Eriksen, H. R., Henrotin, Y., Lahad, A., et al., Chapter 2: European guidelines for prevention in low back pain, November 2004. European Spine Journal. 2006; 15(2): S136-S168.

4. Airaksinen, O., Brox, J. I., Cedraschi, C., Hildebrandt, J., Klaber-Moffett, J., Kovacs, F., et al., Chapter 4: European guidelines for the management of chronic nonspecific low back pain. European Spine Journal. 2006; 15(suppl 2): S192-S300.

5. Dagenais, S., Caro, J., Haldeman, S. A systematic review of low back pain cost of illness studies in the United States and internationally. Spine Journal. 2008; 8: 8-20.

6. Vos, T., Flaxman, A, D., Naghavi, M., Lozano, R., Michaudm C., Ezzati, M., et al., Years lived with disability (YLDs) for 1160 sequelae of 289 diseases and injuries 1990-2010: a systematic analysis for the Global Burden of Disease Study 2010. Lancet. 2012; 380: 2163-2196.

7. Andrusaitis, S. F., Oliveira, R. P., Barros Filho, T. E. Study of the prevalence and risk factors for low back pain in truck drivers in the state of São Paulo, Clinics Journal. 2006; 61: 503-510.

8. Hayden, J. A., van Tulder, M. W., Malmivaara, A., Koes, BW., Exercise therapy for treatment of non-specific low back pain. Cochrane Database Systematic Reviews. 2005: 20.

9. Maher, C., Latimer, J., Refshauge, K. Prescription of activity for low back pain: What works? Australian Journal of Physiotherapy. 1999; 45: 121-132

10. Da Silva, A., Mannrich, G. Pilates nareabilitac, ao:umarevisa osistem'atica. FisioterMov. 2009; 22: 449-455.

11. Muscolino, J. E., Cipriani, S. Pilates and the "powerhouse". Journal of Bodywork and Movement Therapies. 2004; 8: 15-24.

12. Da Fonseca, J. L., Magini, M., de Freitas, T. H. Laboratory gait analysis in patients with low back pain before and after a pilates intervention. Journal of Sport Rehabilitation. 2009; 18: 269-282.

13. Kendall, F. P., Kendall, E. M., Provance, P. G. Muscles: Testing and Function. 4th ed. Baltimore, MD: Williams \& Wilkins; 1993.

14. Vleeming, A., Pool-Goudzwaard, A. L., Stoeckart, R., van Wingerden, J. P., Snijders CJ. The posterior layer of the thoracolumbar fascia. Its function in load transfer from spine to legs. Spine. 1995; 20: 753-758.

15. Janda, V. Muscle weakness and inhibition (pseudoparesis) in back pain syndromes. In: Grieve GP, ed. Modern Manual Therapy of the Vertebral Column. New York, NY: Churchill-Livingstone; 1986

16. Sahrmann, S. A. Posture and muscle imbalance: faulty lumbar pelvic alignment and associated musculo- skeletal pain syndromes. Orthopaedic research and Review. 1992; Nov- Dec: 13-20.

17. Mohan Kumar, G., Jibi paul, Sundaram, M. S., Mahendranath, P., Priya, C., Premnathmargabandhu., Impact of occupation and lifestyle on prevalence of nonspecific low back pain among common population: A crosssectional study. Indian Journal of Public Health Research \& Development. 2019; 10(11): 2118-2123,

18. Mohan Kumar, G., Jibi paul, Sundaram, M. S., Mahendranath, P., Comparative effect of mulligans mobilization versus stabilization exercise on chronic nonspecific low back pain: A pilot study. Indian Journal of Public Health Research \& Development. 2020; 11(1): 12831288.

19. Shobana, V., Mohan Kumar, G., Rajalaxmi, V., Veena Krithika., Yuvarani, G., Sudhakar, S., et al., Comparative study on core strengthening exercises and myofascial release technique for chronic low back pain, Biomedicine: 2019; 39(1): 125-133.

20. Lin, H. T., Hung, W. C., Hung, J. L., Wu, P. S., Liaw, L. J., Chang, J. H. Effects of Pilates on patients with chronic nonspecific low back pain: a systematic review. Journal of Physical Therapy Science. 2016; 28(10): 2961-2969.

21. Jadhav, S.V., Kadu, S., Diwate, A.D. Effectiveness of pilates exercises on non-specific low back pain in nursing students and staff of a tertiary care teaching hospital and nursing college. International Journal of Clinical and Biomedical Research. 2018; 15: 35-37. 